\title{
THE RELATIONSHIP BETWEEN LOCOMOTIVE SYNDROME AND QUALITY OF LIFE IN THE ELDERLY
}

\author{
Nasim Sadeghi Mahali ${ }^{1}$, Mohammad Ali Hosseini², Kian Norouzi Tabrizi ${ }^{3}$ Mehdi Rahgozar4, Seyed Habibollah Kavari ${ }^{5}$
}

${ }_{1}^{1}$ Graduate Student, Iranian Research Center On Aging, University of Social Welfare and Rehabilitation Sciences, Tehran, Iran. ${ }^{2}$ Associate Professor, Department of Rehabilitation, Faculty Member of University of Social Welfare and Rehabilitation Sciences, Tehran, Iran.

${ }^{3}$ Associate Professor, Iranian Research Center on Aging, University of Social Welfare and Rehabilitation Sciences, Tehran, Iran. ${ }^{4}$ Associate Professor, Department of Biomedical and Computer Sciences, Faculty Member of University of Social Welfare and Rehabilitation Sciences, Tehran, Iran.

${ }_{5}^{5}$ Assistant Professor Faculty member of Rehabilitation Management Department, School of Rehabilitation, University of Social Welfare and Rehabilitation Sciences, Tehran, Iran.

ABSTRACT
BACKGROUND
Locomotive system diseases during aging are causes of disability. Locomotive syndrome is a condition where the elderly depends
on nursing care for self-care or will be at risk in near future. This syndrome leads to impairment in daily functioning and self-care,
loss of autonomy, dependence and movement constraints.
The aim of this study was to investigate the association between locomotive syndrome and quality of life in the Qaemshahr
elderly.

\section{MATERIALS AND METHODS}

This study is a descriptive study and from the thesis by available sampling. This study was performed on 120 Iranian elders in 2017. Data collection was done using demographic questionnaire, Geriatric Locomotive Function Scale questionnaire (GLFS-25) and European Quality of Life questionnaire (EQ-5D). Data were analysed using SPSS V23, t-test, Chi-square and R-correlation coefficient.

\section{RESULTS}

According to the results, there was a positive correlation between the scores of the GLFS-25 and EQ-5D questionnaires and a negative correlation with the visual level of health $(p=0.01)$. Also, level of quality of life in two groups with locomotive syndrome and without locomotive syndrome were significantly different (mean differences=-3.3, $p=0.01$ ).

\section{CONCLUSION}

Early diagnosis of LS leads to prevention of physical and psychological effects, increasing the quality of life, reducing the cost of treatment and reducing families and community burden.

\section{KEY WORDS}

Locomotive Syndrome, Quality of Life, Elderly.

HOW TO CITE THIS ARTICLE: Mahali NS, Hosseini MA, Tabrizi KN. The relationship between locomotive syndrome and quality of life in the elderly. J. Evolution Med. Dent. Sci. 2018;7(34):3791-3795, DOI: 10.14260/jemds/2018/850

\section{BACKGROUND}

The elderly population will increase from $10.5 \%$ in 2007 to $21.8 \%$ in 2050.(1) By 2050, the population of the elderly of Iran will be 5 times and it will reach more than 25 million. $(2,3)$ Aging population needs the preparation and predictions in health system policies.(4) From a biological point of view, aging is a total of physiological, psychological, progressive and calm events that begin after puberty and cause structural and functional changes. These changes make the elderly more susceptible to the disease than younger.(5) Increasing life

'Financial or Other Competing Interest': None.

Submission 26-06-2018, Peer Review 03-08-2018,

Acceptance 10-08-2018, Published 20-08-2018.

Corresponding Author:

Seyed Habibollah Kavari,

Assistant Professor Faculty Member of Rehabilitation

Management Department,

School of Rehabilitation,

University of Social Welfare and Rehabilitation Sciences,

Tehran, Iran.

E-mail: kavarih@gmail.com

DOI: $10.14260 /$ jemds $/ 2018 / 850$

(c) $($ ) $\$$ expectancy without disability is an important indicator in assessing the level of public health and the capabilities of a community. Diseases of the locomotive system are one of the causes of the disability in elderly. Most of these problems are related to the musculoskeletal system.(6) The locomotive syndrome is referred to as the condition that the elderly is dependent on nursing services for self-care or in the future, while this condition is related to impaired functioning of one of the motor and motion-dependent organs.(7,8) In recent years, special attention has been paid to the quality of life of the elderly, its dimensions and relation with other health conditions. According to the WHO definition, quality of life, people's perception of their position in life from the point of view of their community's culture and values, goals, expectations, standards and priorities. ${ }^{(9)}$ Evaluating the quality of life is an effective method for assessing their functional independence. Diseases of the locomotive system cause chronic pain in the joints, impairment in daily functioning and self-care, limitation of mobility, dependence and loss of autonomy, and ultimately a reduced quality of life. $(6,10,11)$ The aim of this study was to determine the association between LS and quality of life among elderly residents in the Qaemshahr County. 


\section{MATERIALS AND METHODS}

This study is part of a Descriptive study and approved by the Ethics Committee of Tehran University of Social Welfare and Rehabilitation Sciences. Samples were collected from the elderly in various urban spaces with available convenient sampling method, based on inclusion and exclusion criteria during the period from July 2017 to August 2017. The sample size study was determined according to correlation analysis. Considering the results of previous studies and one-sided research hypothesis, the lowest $\mathrm{R}$ was considered equal to 0.3 $(\alpha=0.05, \beta=0.05)$. As the formula 116 samples were needed, which the researcher sampled 120 people. In this study, 120 elderly residents in the Qaemshahr county $(60 \geq 74$ men, 46 women) participated in the study to determine the relationship between locomotive syndrome and quality of life.

\section{Inclusion Criteria}

1. Individuals $\geq 60$ years old of either sex.

2. Individuals who can check and answer questionnaires by themselves.

3. The satisfaction to participate in the research.

4. Life in Iran and Persian language ability.

\section{Exclusion Criteria}

1. Individuals who are unable to walk without assistance from another person.

2. Individual with brain disease or severe cardiovascular, pulmonary or renal disease.

3. Individuals with mental illness.

4. Individuals with the history of fractures of the lower extremities and/or spine within the preceding 6 months.

5. Individuals who are receiving treatments for acute trauma.

The demographic questionnaire, the Geriatric locomotive function scale-25 and the European quality of life questionnaire were used. The locomotive questionnaire was created by the Japanese Orthopedic Association in 2012. The questionnaire contains 25 questions including 4 questions for pain assessment, 17 questions related to daily activities and the quality of life of the elderly, and 4 questions related to social and psychological functioning. Each item is rated 0 to 4 on a Likert scale. Total score is 0 to 100 points. $(6,7)$ More points mean more movement impairment. Cut-off point is 16 . Individuals with a score of 16 upward are in the group with LS. The psychometric of tool in Iranian elderly have been confirmed. The reliability results in the test-retest method and Cronbach's alpha were 0.84 and 0.93 , respectively,(12) $(\mathrm{p}=0.01)$. European quality of life questionnaire was used to assess the quality of life of the elderly. This standard questionnaire has five questions related to quality of life, which assesses five dimensions of mobility, self-care, lifestyle activities, pain, anxiety and depression. The questionnaire is scored on a 3-point scale from 0 to 2 points. Reliability of the tool by test-retest and validity and variance analysis showed that this questionnaire has credibility in Iranian elderly.(13) The validity and reliability of the questionnaire for various components have been reported from 0.77 to 0.88 . The Cohen coefficient of Kappa is obtained between 0.61 and 1.(14) EQ-5D questionnaire is shorter than other quality of life questionnaires. This tool is translated into 172 languages. Self-perceive Health (VAS) rating scale from 0 to 100 , which is marked by the participant. A higher score on the chart represents more health.(15) Initially, the researcher explained the research objectives to the samples, then he was informed for participation in the study of informed consent. Participation in the study was voluntary and all samples were free to leave the study. All data were analysed using SPSS version 23, unpaired t-test, Chi-square and R-correlation coefficient. P-value was considered to be 0.05 .

\section{RESULTS}

120 elders ( 74 males and 46 females) with a mean age of 67.5 \pm 5.9 years participated in this study. The mean age of subjects in the LS group was $71.4 \pm 7.9$ and in the nonlocomotive syndrome group was $67.5 \pm 5.9$, which was statistically significant $(\alpha=0.05$ and sig= 0.009 ). Most people were aged 60 - 69 (55.9\%). 74.2\% were married, 50\% were retired, $76.7 \%$ had at least one chronic disease, $48.3 \%$ had chronic pain history and $49.2 \%$ had a history of fall Table 1 . $85.8 \%$ had diploma education and higher than diploma. The frequency of chronic diseases is presented in Table 2 . Pearson correlation coefficient was calculated between the GLFS-25 questionnaire and the EQ5D questionnaire and the VAS of the health level were equal to 0.86 and -0.77 respectively and were significant at the $\mathrm{p}=0.01$. These results indicate a significant positive association between locomotive syndrome and low quality of life in the elderly. Also, there was a significant negative association between locomotive syndrome and self-perception of health (Table 3).

In the next step, the samples were divided into two groups: locomotive syndrome and non-locomotive syndrome. The cut-off point was determined at 16. Differences between age and sex variables in two groups were calculated using $\mathrm{T}$ test and Chi-square test. According to Chi-square, there was a significant correlation between gender and LS ( $p=0.05$, sig= 0.01 ). It is necessary to know that the T-statistic for the comparison of the mean of two independent samples with equal variance in comparison with the two groups with unequal variance is not the same. Therefore, we used the Levene's test and the condition for inequality of variances to test the research hypothesis. Based on the T-test, there was a significant difference. The mean score of the GLFS-25 and EQ$5 \mathrm{D}$ questionnaires between the two groups $(\mathrm{p}=0.05$, sig $=0$ ). Also, T-test was used to examine the difference between the mean score of the GLFS-25 questionnaire and the VAS of health in two groups. According to the Levene's test ( $\operatorname{sig}>\alpha$ ), the HO hypothesis is accepted. Considering the values $(\mathrm{p}=$ 0.05 , sig $=0$ ), we can say that the average level of health reported by individuals in the two groups is significantly different (Table 4).

\begin{tabular}{|c|c|c|}
\hline Variable & & $\begin{array}{c}\text { The Number } \\
\text { (Percentage) }\end{array}$ \\
\hline \multirow{3}{*}{ Age } & $60-64$ & $32(26.7 \%)$ \\
& $65-69$ & $35(29.2 \%)$ \\
& $70-74$ & $22(18.3 \%)$ \\
& $75-79$ & $16(3 / 13)$ \\
Marital status & 80 years up & $15(5 / 12)$ \\
& Single & $4(3.3 \%)$ \\
& Married & $89(74.2 \%)$ \\
Chronic disease & Widow or divorced & $27(22.5 \%)$ \\
& Yes & $92(76.7 \%)$ \\
& No & $28(23.3 \%)$ \\
\hline
\end{tabular}




\begin{tabular}{|c|c|c|c|c|c|c|c|c|}
\hline \multicolumn{5}{|c|}{$\begin{array}{l}\text { History of chronic pain } \\
\text { (More than } 6 \text { months) } \\
\text { There is no history of chronic pain }\end{array}$} & \multicolumn{4}{|c|}{$\begin{array}{l}58(48.3 \%) \\
62(51.7 \%)\end{array}$} \\
\hline \multicolumn{5}{|c|}{$\begin{array}{l}\text { There is no fall history } \\
\text { The record has a fall once } \\
\text { The record has fallen } 2 \text { times } \\
\text { The record has } 3 \text { falls and more }\end{array}$} & \multicolumn{4}{|c|}{$\begin{array}{c}61(50.8 \%) \\
38(31.7 \%) \\
14(11.7 \%) \\
7(5.8 \%) \\
\end{array}$} \\
\hline \multicolumn{9}{|c|}{ Table 1. Frequency of Variables } \\
\hline & 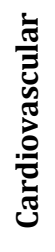 & $\begin{array}{l}\stackrel{0}{\frac{d}{d}} \\
\frac{0}{0} \\
\frac{0}{0}\end{array}$ & 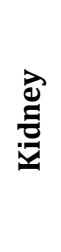 & 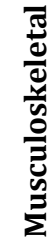 & 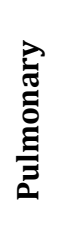 & 节 & 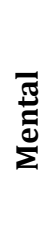 & 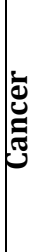 \\
\hline Frequency & 67 & 21 & 17 & 20 & 4 & 4 & 7 & 1 \\
\hline
\end{tabular}

\begin{tabular}{|c|c|c|}
\hline Variables & $\begin{array}{c}\text { Pearson } \\
\text { Correlation } \\
\text { Coefficient }\end{array}$ & $\begin{array}{c}\text { P value } \\
\text { N=120 }\end{array}$ \\
\hline $\begin{array}{c}\text { GLFS-25 questionnaire scores * } \\
\text { EQ5D questionnaire scores }\end{array}$ & 0.858 & 0.01 \\
\hline $\begin{array}{c}\text { GLFS-25 questionnaire scores * } \\
\text { VAS scores }\end{array}$ & -0.772 & 0.01 \\
\hline \multicolumn{2}{|c|}{ Table 3. Association between LS and QOL } \\
\hline
\end{tabular}

$\mathrm{P}<0.01$

\begin{tabular}{|c|c|c|c|c|c|}
\hline & Mean of & \multicolumn{2}{|c|}{ Sex } & \multirow{2}{*}{ Total } & \\
\cline { 3 - 4 } & Age & Male & Female & & df= 1 \\
\hline LS positive & $71.4 \pm 7.8$ & 34 & 35 & 69 & sig= 0.01 \\
LS negative & $67.5 \pm 5.9$ & 40 & 11 & 51 & $\mathbf{p}<\mathbf{0 . 0 5}$ \\
Total & & 74 & 46 & 120 & \\
\hline \multicolumn{5}{|c}{ Table 4. Chi-Square Test Result } \\
\hline
\end{tabular}

\begin{tabular}{|c|c|c|c|c|c|}
\hline & $\begin{array}{c}\text { LS } \\
\text { Group } \\
\text { N= 69 }\end{array}$ & $\begin{array}{c}\text { Non-LS } \\
\text { Group } \\
\text { N=51 }\end{array}$ & \multicolumn{3}{|c|}{$\begin{array}{c}\text { T-Test for Equality } \\
\text { of Means } \\
\text { P= 0.05 }\end{array}$} \\
\hline & & & $\mathbf{T}$ & $\begin{array}{c}\text { Sig } \\
(\boldsymbol{\alpha = 0 . 0 5})\end{array}$ & $\begin{array}{c}\text { Mean } \\
\text { Differences }\end{array}$ \\
\hline $\begin{array}{c}\text { GLFS-25 } \\
\text { score }\end{array}$ & $\begin{array}{c}32 \pm \\
13.9\end{array}$ & $\begin{array}{c}7.8 \pm \\
4.54\end{array}$ & -11.9 & 0.00 & -24.1 \\
\hline $\begin{array}{c}\text { EQ5D } \\
\text { score }\end{array}$ & $\begin{array}{c}4.6 \pm \\
1.9\end{array}$ & $\begin{array}{c}1.3 \pm \\
1.05\end{array}$ & -11.3 & 0.00 & -3.3 \\
\hline $\begin{array}{c}\text { Eq. VAS } \\
\text { score }\end{array}$ & $\begin{array}{c}53.4 \pm \\
15.9\end{array}$ & $\begin{array}{c}14.6 \pm \\
80.1\end{array}$ & 9.4 & 0.00 & 26.7 \\
\hline \multicolumn{7}{|c|}{ Table 5. Mean Scores in Two Groups (LS and Non-LS) } \\
and T-Test Result
\end{tabular}

\section{DISCUSSION}

Results of our study showed that there was a strong positive correlation between locomotive syndrome and low quality of life and people with locomotive syndrome reported lower quality of life. Quality of life and perceived health had a moderate correlation based on average scores of the questionnaire and VAS. The result of our study was confirmed by previous studies. Saeedi Mehr et al (2016) reported that among the elderly, quality of life is moderate.(16) Zahmatkesh and colleagues (2015) reported that quality of life in Bushehr's elderly is less than 50.(17) Ahmadi et al (2004) with the same goal in Zahedan, they reported that quality of life is weak in all dimensions of the questionnaire.(18) Darvishpoor (2010), Kakhki and Abed Saidi (2013) have reported that Tehranian elderly quality of life is in different dimensions of the questionnaire. $(19,20)$ But other studies have found other results. Ashayeri and Nejati (2008) stated that quality of life in elderly was moderate-to-high.(21) Salarilak et al (2009), in evaluating the quality of the elderly in the city of Kamyaran, found that the quality of life in the elderly was at a desirable level (50 with a standard deviation of 10).(22)

LS is a new construct in medicine. Clinical studies on this concept are few. Hirano et al, in study entitled "Impact of LS on the quality of life in the elderly concluded that there is a significant relationship between the LS and quality of life. The results of other studies suggest that LS and musculoskeletalskeletal disorders lead to poor quality of life.(23) Few studies have examined the relation between quality of life and LS worldwide, but there are studies that examined the effects of musculoskeletal disorders on quality of life. To better understand the construct of LS, the dimensions of the construct should be explored and fully explained. It seems that LS is associated with degenerative musculoskeletal diseases such as spondylosis, osteoporosis and osteoarthritis. These diseases are the most common musculoskeletal disorders in the elderly, requiring special attention. Many studies have examined the relationship between quality of life and musculoskeletal disorders. Ghasemi and Chabok (2011) measured the quality of life in patients with low back and knee arthritis in Mashhad. They found that these patients had lower quality of life.(24) Nasiri and colleagues (2015) studied the relationship between musculoskeletal disorders associated with work and quality of life in nurses. They found that there was a meaningful relationship between these two variables ( $p=0.05, \beta=0.05)$. Whatever disorders increase, the quality of life is lower.(25) Tabatabaei (2017) reported that there is a significant relationship between skeletal disorders and quality of life dimensions, and these diseases are associated with a decrease in the quality of life.(26) Picavet and Hoeymans (2008) say locomotive fractures result in pain and reduced physical performance. Due to the high prevalence of these diseases and the direct impact on quality of life, they should be carefully followed and treated.(27) In a prospective study for 28 months, Ruck and colleagues found that musculoskeletal disorders have a negative impact on the various dimensions of quality of life (physical, social and psychological). They emphasised that screening disorders require timely interventions and treatments.(28) Previous studies confirm the link between quality of life and musculoskeletal disorders.(29-31) The result of this study is the same with the study in Japan. The results of Pearson correlation coefficient show that there is a significant correlation between the scores of the GLFS-25 and EQ-5D ( $\mathrm{r}=$ $0.85, \mathrm{p}=0.01$ ). EQ-5D questionnaire used to measure the quality of life in elders. Individuals in the LS group received lower scores from the quality of life questionnaire than nonLS. $87 \%$ of elders have history of one or more chronic diseases. The frequency of musculoskeletal disorders in this group was $33.3 \%$. Considering the validity of the results of the questionnaire, its simplicity and ease of use in the elderly population, the strong relationship between LS and different dimensions of quality of life and the use of this questionnaire is highly recommended. As mentioned above, there are 
studies to show the relation between LS and quality of life already.

\section{CONCLUSION}

The results of the research show that there is a direct relationship between LS and low levels of quality of life in elderly. Clearly, persons with LS have lower score from EQ$5 \mathrm{D}$ too. $\mathrm{LS}$ is a useful measure for screening people with motor disorders, so learning about this construct should be used to reduce the incidence and prevalence of LS in the community. Early diagnosis of LS leads to prevention of physical and psychological effects, increasing the quality of life, reducing the cost of treatment and reducing families and community burden. Due to the nature of the job, nurses play an important role in teaching, consulting and screening of older people at risk for development of locomotive syndrome.

\section{Research Limit}

Due to the limited access to eligible samples in study, it is recommended that study be done in a larger, randomised sample.

\section{ACKNOWLEDGEMENT}

We thank and appreciate the support of Dr. Rahgozar, who helped the researcher in statistical analysis.

\section{REFERENCES}

[1] Mirzaei M, Ghahfarookhi MS. Demographics of the elderly population in Iran, according to the census of 1335 to 1385 . Elder 2008;2(5).

[2] Haghshenas N. Sociological aspects and population aging. Journal of Sociological Studies 2012;1(2).

[3] Shahbazi M, Mirkhani M, Hatamizadeh N, et al. Disability assessment in elderly people in Tehran city (Persian). Iranian Journal of Ageing 2008;3(3-4):8492.

[4] Asgarifar G. Elderly disease. Tehran: University of Rehabilitation Sciences and Social Welfare, 2015.

[5] Ahmadikamrani A. Epidemiology of aging memory and cognition in old age. Tehran: Elderly Research Center, University of Rehabilitation Sciences and Social Welfare, 2015.

[6] Tavares DR, Santos FC. Locomotive syndrome in the elderly: translation, cultural adaptation and Brazilian validation of the tool 25-Question Geriatric Locomotive Function Scale. Rev Bras Reumatol Engl Ed 2017;57(1):56-63.

[7] Seichi A, Hoshino Y, Doi T, et al. Development of a screening tool for risk of locomotive syndrome in the elderly: the 25-question Geriatric Locomotive Function Scale. J Orthop Sci 2012;17(2):163-72.

[8] Nakamura K. A "super-aged" society and the "locomotive syndrome". Journal of Orthopaedic Science 2008;13(1):1-2.

[9] Bonomi AE, Patrick DL, BushnelL DM, et al. Validation of the United States' version of the World Health Organization Quality of Life (WHOQOL) instrument. J Clin Epidemiol 2000;53(1):1-12.

[10] Meiner SE. Gerontologic Nursing. $5^{\text {th }}$ edn. USA: Evolve/Elsevier 2015.
[11] Nakamura K, Ogata T. Locomotive syndrome: definition and management. Clinic Rev Bone Miner Metab 2016;14(2):56-67.

[12] Mahali NS, Hosseini MA, Rahgozar M, et al. Evaluation of cultural adaptation, validity and reliability of the questionnaire of Geriatric Locomotive Function Scale 25 questions. Pharmacophore 2017;8(6S):e1173929, p. 5.

[13] Rouhani S. The relative efficiency of public and nonpublic health centres in Iran. University of Keele, UK: 2006.

[14] Adib A, Abasiniya M. Evaluation of health-related quality of life in elderly patients with femoral neck fracture with two tools SF36 and EQ-D5. Nursing Research 2010;5(15).

[15] Safa A, Adib-Hajbaghery M, Fazel-Darbandi AR. Relationship between sleep quality and quality of life in older adults. Iranian Journal of Psychiatric Nursing 2015;3(3):53-62.

[16] Saeidimehr S, Geravandi S, Izadmehr A, et al. Relationship between the "Quality of Life" and symptoms of depression among older adults. Iranian Journal of Ageing (Salmand) 2016;11(1):90-9.

[17] Zahmatkeshan N, Bagherzade R, Akaberiyan S, et al. Evaluation of quality of life and its related factors in elderly people in Bushehr. Journal of Fasa University of Medical Sciences 2015;2(1):53-8.

[18] Ahmadi F, Salar A, Faghihzade S. Elderly quality of life in Zahedan. Quarterly Journal of Hayat 2004;10(3):617.

[19] Kakhki AD, Saeedi JA. Investigating factors related to the quality of life of the elderly in Tehran. Journal of Nursing and Midwifery Faculty 2013;23(82):6-16.

[20] Darvishpoor KA, Saeedi JA, Delavar A, et al. Measurement tools for health and quality of life in the elderly. Journal of Faculty of Medicine 2010;33(3):162-73.

[21] Nejati V, Ashayeri H. Health-related quality of life among elderly in Kashan (Persian). Iranian Journal of Psychiatry and Clinical Psychology 2008;14(1):56-61.

[22] Salarilak S, Gorgin LK, Amiri S. Evaluating the quality of life of the elderly in the city of Kamyaran in 2009. Urmia Medical Sciences 2013;24(1):24-9.

[23] Hirano K, Imagama S, Hasegawa Y, et al. The influence of locomotive syndrome on health-related quality of life in a community-living population. Mod Rheumatol 2013;23(5):939-44.

[24] Ghasemi G, Chabok A. The effect of physiotherapy services on quality of life in patients with waist and knee arthritis in Mashhad. Tehran: University of Rehabilitation Sciences and Social Welfare, 2010.

[25] Ghabaee DNZ, Haresabadi M, Nesami MB, et al. Musculoskeletal disorders related to work and its relationship with quality of life in nurses. Ergonomics Magazine 2016;4(1):39-46.

[26] Tabatabaei Sh, Jazani RK, Kavousi A, et al. Relationship between musculoskeletal disorders and quality of life in employees of selected hospitals in Golestan Province. Journal of Health Research in Community 2017;3(1):45-56. 
[27] Picavet H, Hoeymans N. Health related quality of life in multiple musculoskeletal diseases: SF-36 and EQ-5D in the DMC $<$ sub $>3</$ sub $>$ study. Annals of the Rheumatic Diseases 2004;63(6):723-9.

[28] Roux $\mathrm{CH}$, Guillemin F, Boini S, et al. Impact of musculoskeletal disorders on quality of life: an inception cohort study. Annals of the Rheumatic Diseases 2005;64(4):606-11.

[29] Antonopoulou MD, Alegakis AK, Hadjipavlou AG, et al. Studying the association between musculoskeletal disorders, quality of life and mental health. A primary care pilot study in rural Crete, Greece. BMC Musculoskeletal Disorders 2009;10(1):143.
[30] Juul-Kristensen B, Ostengaard L, Hansen S, et al. Generalised joint hypermobility and shoulder joint hypermobility, - risk of upper body musculoskeletal symptoms and reduced quality of life in the general population. BMC Musculoskeletal Disorders 2017;18(1):226.

[31] Abbott JH, Usiskin IM, Wilson R, et al. The quality-oflife burden of knee osteoarthritis in New Zealand adults: a model-based evaluation. PLoS One 2017;12(10):e0185676. 